\title{
Conformational Analysis of Seven Membered Nitrogen Heterocycles Employing Molecular Modeling. Part II: 1-(O- Nitrophenyl)-2-Phenyl-1h-4,5,6,7-Tetrahydro-1,3-Diazepine
}

\author{
Mónica E. Hedrera, Adriana Robinsohn and Isabel A. Perillo \\ Departamento de Química Orgánica. Facultad de Farmacia y Bioquímica. Universidad de Buenos Ai- \\ res. Junín 956 (1113). Buenos Aires, Argentina \\ E-mail: iperillo@ffyb.uba.ar
}

\begin{abstract}
Geometry optimization of 1-(o-nitrophenyl)-2-phenyl-1H-4,5,6,7-tetrahydro-1,3diazepine is performed by means of molecular modeling. Results are correlated with theoretical and experimental UV spectra.
\end{abstract}

\section{Introduction}

As a part of our study about seven-membered cyclic amidines, we report here the conformational analysis of 1-(o-nitrophenyl)-2-phenyl- $1 \mathrm{H}$-4,5,6,7-tetrahydro-1,3-diazepine $1\left(\mathrm{Ar}=o-\mathrm{NO}_{2} \mathrm{C}_{6} \mathrm{H}_{4}\right) \mathrm{em}$ ploying computer molecular modeling, being this study a continuation of another one about the conformational analysis of 1-(p-nitrophenyl)-2-phenyl-1H-4,5,6,7-tetrahydro-1,3-diazepine $(\mathbf{1}, \operatorname{Ar}=p$ $\left.\mathrm{NO}_{2} \mathrm{C}_{6} \mathrm{H}_{4}\right)[1]$.

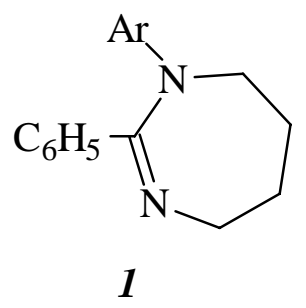

\section{Experimental}

Conformational space was explored by means of molecular mechanics. Thus, potential energy maps were obtained varying all dihedral angles belonging both to the seven-membered ring and to the substituents, employing MMX as implemented in the software PCModel for Windows. Conformations corresponding to minimum energy of these surfaces, were taken as input structures for Molecular Dynamics procedure, employing $\mathrm{MM}^{+}$as implemented in HYPERCHEM 5.1. Conformations were reoptimized at the AM1 level as implemented in HYPERCHEM 5.1. 
Conformations which presented $\Delta\left(\Delta \mathrm{H}_{\mathrm{f}}\right)>3 \mathrm{kcal} / \mathrm{mol}$ with the others were discarded. Theoretical ultraviolet-visible spectra were calculated for all different geometries obtained, and compared with the experimental spectra performed in chloroform solution. Those geometries, whose theoretical UVvisible spectra better fitted experimental one, were selected for the final analysis.

\section{Results and Discussion}

Bond lengths and angles, dihedral angles, improper torsion angles and charge densities were measured for the remaining conformations.

Five chairs and eleven twisted boats were obtained in this way for compound $\mathbf{1}\left(\mathrm{Ar}=O-\mathrm{NO}_{2} \mathrm{C}_{6} \mathrm{H}_{4}\right)$. The higher number of conformations corresponding to minimum energy than those previously found for $1\left(\mathrm{Ar}=p-\mathrm{NO}_{2} \mathrm{C}_{6} \mathrm{H}_{4}\right)$ [1] proved to be due to different orientation of the unsymmetrical $o$ nitrophenyl substituent.

Hybridization of $\mathrm{N} 1$ resulted between $\mathrm{sp}^{2}$ and $\mathrm{sp}^{3}$, independently of the predetermined hybridization considered in the input structure, as it was observed for compound $\mathbf{1}\left(\mathrm{Ar}=p-\mathrm{NO}_{2} \mathrm{C}_{6} \mathrm{H}_{4}\right)$ [1]. However, $\mathrm{N} 1-\mathrm{C}_{\mathrm{ipso}}$ bond length showed absence of conjugation between $\mathrm{N} 1$ lone pair and $o$-nitrophenyl substituent, in contrast to those results previously obtained for the $p$-nitrophenyl derivative $\mathbf{1}\left(\mathrm{Ar}=p-\mathrm{NO}_{2} \mathrm{C}_{6} \mathrm{H}_{4}\right)$ [1].

\section{References and Notes}

1. Hedrera, M.; Robinsohn, A.; Perillo, I. "Conformational analysis of seven-membered nitrogen heterocycles using molecular modeling: 1-aryl-2-phenyl-1H-4,5,6,7-tetrahydro-1,3-diazepines", Presented in the International Congress of Heterocyclic Chemistry, Bozeman, Montana, agosto de 1997. 